\author{
3. CONVERSACIONES \\ 3. Conversations
}

\title{
LA PROFESORA ANGELA GIALLONGO Y EL FASCINANTE MUNDO \\ DE LA IMAGINACIÓN EN LA HISTORIA DE LA EDUCACIÓN
}

\section{Professor Angela Giallongo and the fascinating world of imagination in the History of Education}

\author{
Antonella Cagnolati \\ Universidad de Foggia (Italia). Departamento de Humanidades \\ Correo-e: antonella.cagnolati@unifg.it
}

Recepción: Io de abril de 20I6. Envío a informantes: 20 de abril de 2016 Aceptación definitiva: 8 de junio de 2016

$\mathrm{E}$

l perfil científico de Angela Giallongo, catedrática desde el 200 i de Historia de la Educación, en el Departamento Discui (Universidad de Urbino, Italia), se sitúa en el siempre halagüeño y consolidado sector, a nivel internacional, de los estudios de género y de la infancia.

El corte privilegiado de su investigación se centra en los desconocidos procesos de educación informal. Procesos que se pueden detectar en las experiencias gestuales y sensoriales, en las dinámicas emotivas y en los estándares del imaginario. Procesos que implícitamente modelaron la formación de las generaciones pasadas, y no solo. Sus análisis a partir de la base de diferentes escuelas de pensamiento (Elias, Les Annales, Rosenwein, Reddie, Durand y otros/as estudiosos/ as de la última generación) entrelazan las categorías de las mentalidades con los regímenes emotivos en los procesos formativos de larga duración.

Por este motivo, han recobrado fuerza e impulso la historia de la infancia, de la asimetría sexual y de los estereotipos mentales y visuales -todavía presentesen las estrategias educativas europeas modernas y contemporáneas.

En la primera fase de la investigación se desvelaron los dualismos, las ideologías y las jerarquías sensoriales que construyeron la «corporeidad» en la tradición de paidéutica occidental. 


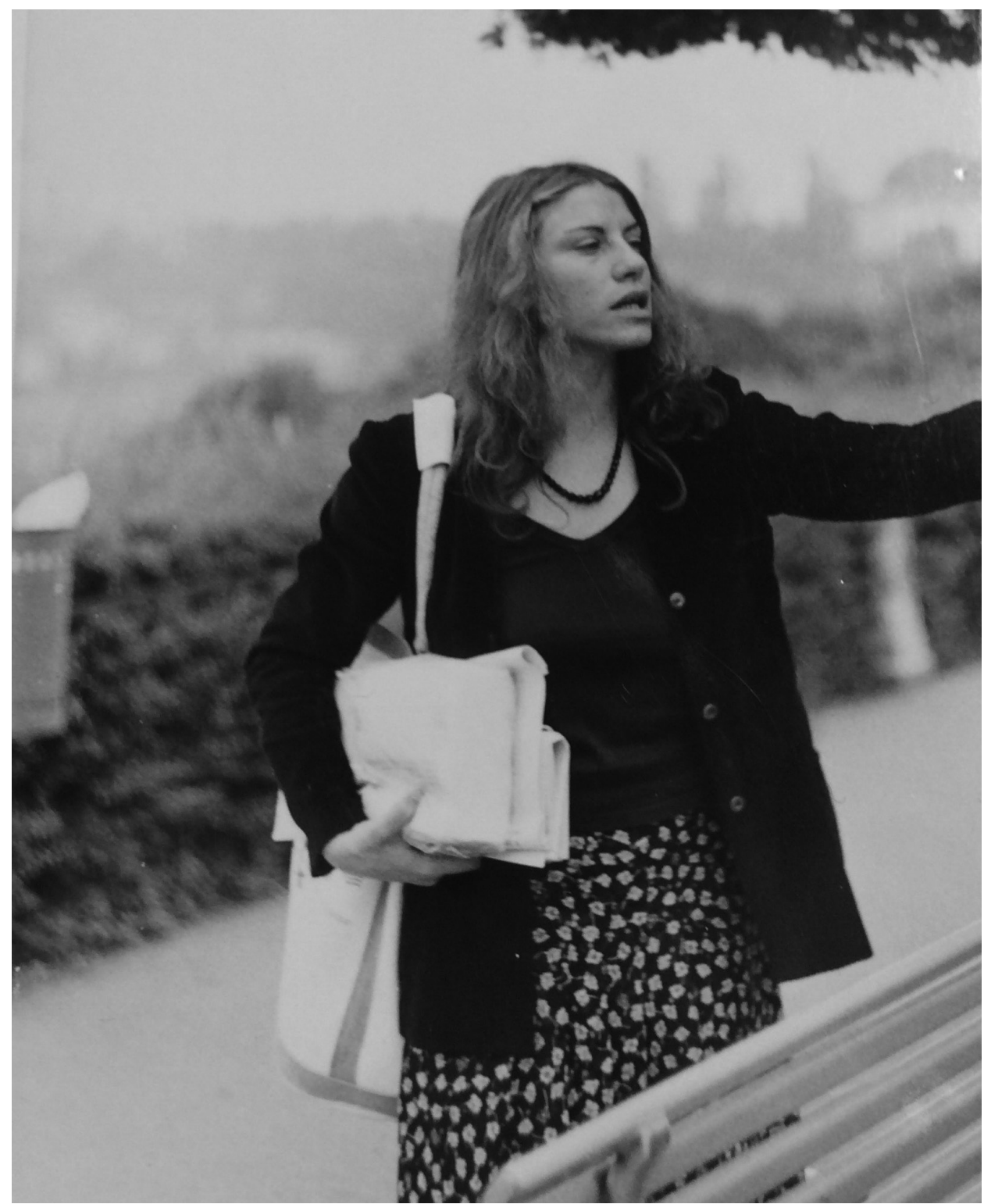

La profesora Giallongo al principio de su carrrera académica (años 80).

La elección abrió el camino a otros campos:

- la función del lenguaje gestual en las diferencias de género transmitidas en las sociedades premodernas;

- las teorías francesas, italianas y españolas acerca de los modales dirigidas principalmente a las mujeres, durante los siglos finales de la Edad Media; 
LA PROFESORA ANGELA GIALLONGO Y EL FASCINANTE MUNDO DE LA IMAGINACIÓN EN LA HISTORIA DE LA EDUCACIÓN

ANTONELLA CAGNOLATI

- el empleo pedagógico del paseo en el siglo Xviır;

- los nuevos comportamientos sensoriales en la civilización postindustrial;

- la historia conceptual, simbólica y social de la mirada;

- el uso de imágenes en la investigación histórico-educativa informal.

Poco a poco se han perfilado ulteriores investigaciones: desde los estereotipos sobre la feminidad en el neomedievalismo imperantes en la educación familiar italiana del siglo xIx hasta la exploración de las representaciones sociales de la infancia en Europa. De ahí que se realizara la traducción en italiano para Dédalo, en 2002, de La Historia de la infancia di Buoenaventura Delgado.

Curiosidades paralelas se realizaron en algunos exponentes del cognitivismo contemporáneo (Piaget, Bruner y Gardner) por lo que atañe a la utilidad de la investigación histórica para comprender los procesos mentales y en la enseñanza de esta disciplina en la escuela obligatoria y en la universitaria (1940-1970) en Italia.

Los resultados de dicha investigación se dieron a conocer, a nivel nacional, y en el extranjero a través de publicaciones, con participaciones en doctorados, convenciones, conferencias y seminarios.

\section{¿Cuáles son para ti los años formativos más importantes durante la etapa universitaria?}

Por supuesto los del 68. Para lo que a mí se refiere, el primer acercamiento con el período de protesta fue directo y se remonta a la experiencia de una estudiante de la Facultad de Pedagogía de la Universidad de Urbino. Volver a pensar en aquellos años, especialmente para quien se consagró a la historia, incita a apelar a su sentido de cambio, sin tentaciones hagiográficas y oleográficas y a preguntarse, en primer lugar, si todo lo que se aprendía en aquel momento provenía de libros o de compromisos prácticos.

Sin duda, en el 68, como ahora, prevalecía la «tendencia a hacer», a actuar con laetetia -y, como diría Spinoza, con el estado de ánimo óptimo para cada acciónsin tener que recurrir siempre a los beneficios de la reflexión. Sin embargo, se leían textos que nunca nadie había buscado en las librerías.

Circulaban libros de Marx, Marcuse, Dewey, de Beauvoir, Malcom X, Bloch, Reiche, Illich, Neil, Freire... Estos pensadores alimentaban los debates sobre la división de clase, de género, sobre la familia, sobre la educación democrática y libertaria, sobre todo lo que podía volver a forjar la cultura.

Por tanto, yo pertenezco a esa generación que ocupó las facultades y siguió los pasos de la tradición humanista, iniciada por Aristóteles, creyendo en el principio de bien vivre de la comunidad y los relativos valores de la educación a la libertad y la felicidad.

Esta utopía era apasionante, estimulante.

Ofrecía la posibilidad de llegar a ser protagonistas de un cambio histórico. La participación en las primeras asambleas y en los trabajos en grupo invertía toda nuestra experiencia de estudiantes. 


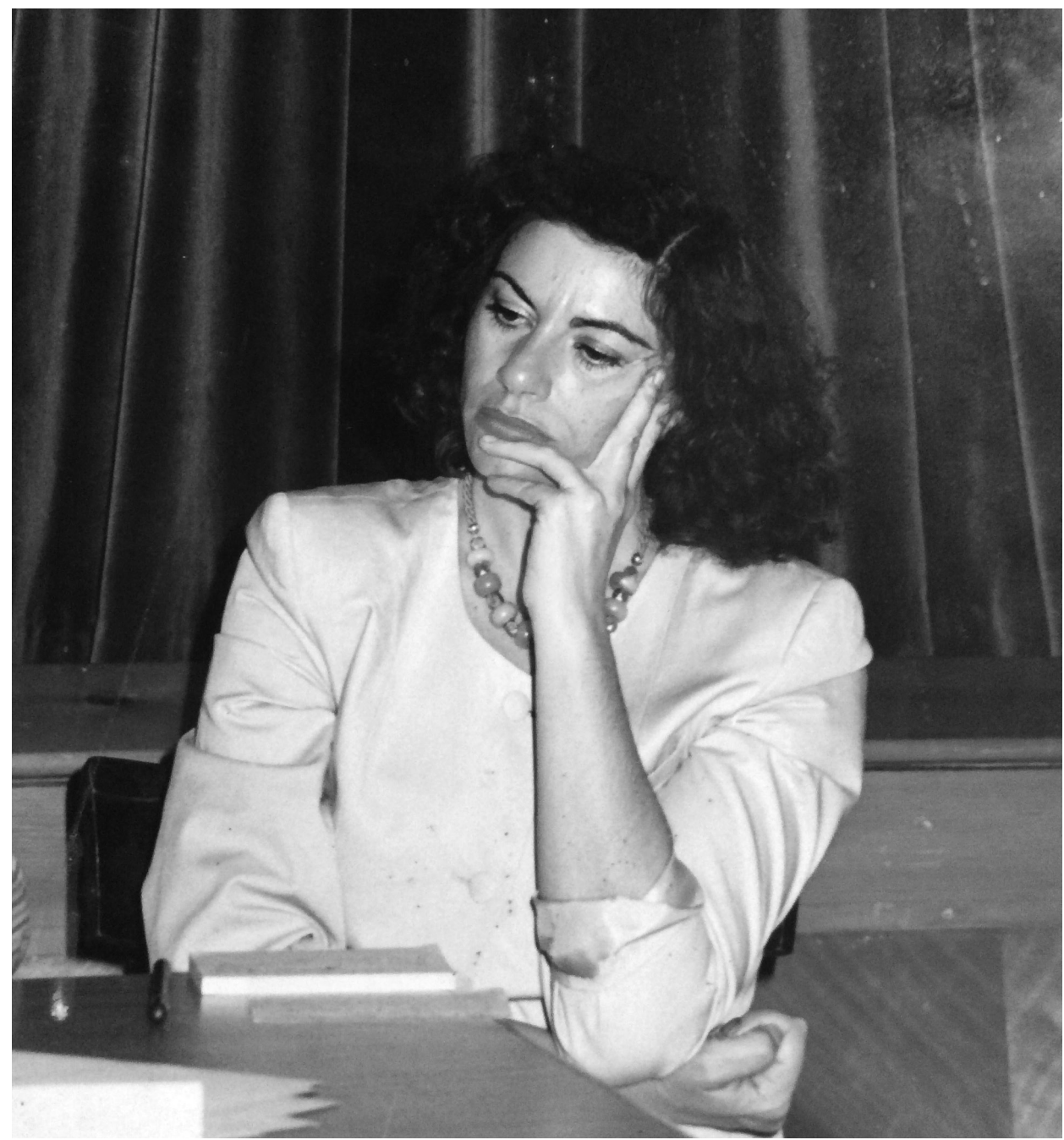

La profesora Giallongo en el Congreso sobre la Historia de la Educación organizado en la Universidad del Salento (1984).

Tanto es así que en el torbellino del cambio aparecieron nuevos tipos humanos.

La transformación de los cuerpos durante esta experiencia es la prueba más evidente.

Recuerdo perfectamente cómo la melena revolucionaria reemplazó el corte militar de los chicos, mientras que las cabezas cardadas de las chicas dejaban paso a largas cabelleras despeinadas.

La humanidad inquieta del 68 no se conformaba con sobrevivir en el anonimato: estaba electrizada con el deseo de poder cambiar el deseo, a partir justamente de las aulas. 
LA PROFESORA ANGELA GIALLONGO Y EL FASCINANTE MUNDO DE LA IMAGINACIÓN EN LA HISTORIA DE LA EDUCACIÓN ANTONELLA CAGNOLATI

El volver a poner en discusión el sistema universitario formaba parte integral de la reforma de la justicia social en el mundo. Esta utopía guiaba nuestra imaginación simultáneamente hacia el futuro y hacia el pasado: queríamos volver a dar un nuevo sentido también a la historia.

La historia de la pedagogía nos quedaba pequeña.

\section{¿Y entonces cuánto influyó esta experiencia en tu pasión por la historia?}

Muchísimo. Potenció en mí la idea de la investigación histórica como herramienta de transformación social.

\section{¿Bastaba la pasión?}

Te contesto con una metáfora. Esta era la levadura. La pasta debía conseguirla con la metodología.

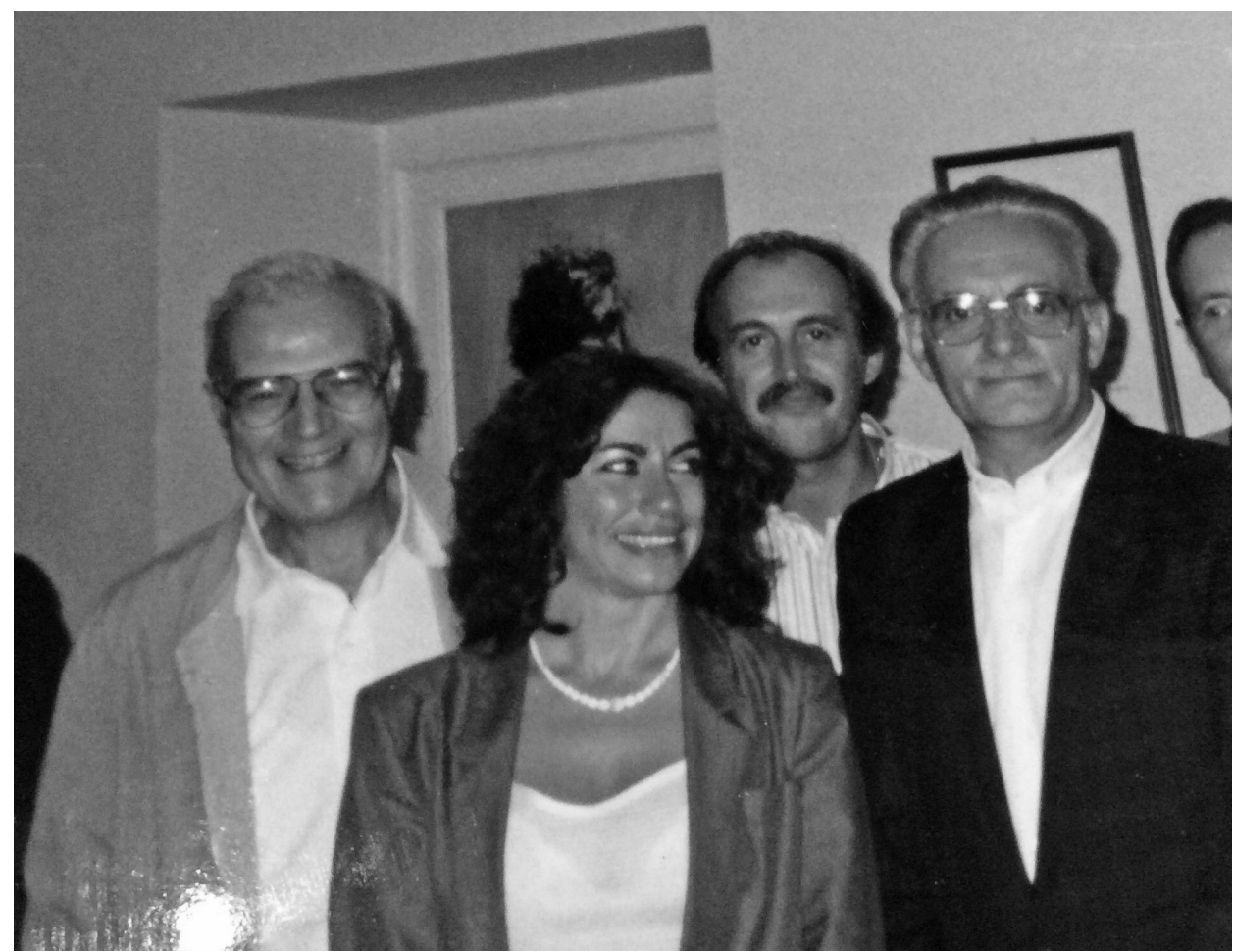

La profesora Giallongo con los colegas de la Facultad de Pedagogía de la Universidad de Urbino (años 9o). 
LA PROFESORA ANGELA GIALLONGO Y EL FASCINANTE MUNDO DE LA IMAGINACIÓN EN LA HISTORIA DE LA EDUCACIÓN ANTONELLA CAGNOLATI

¿Tus enfoques metodológicos han cambiado a lo largo del tiempo?

No, no creo. Desde las primeras investigaciones siempre he mantenido presente la lección de Les Annales, echando mano de las aportaciones de diferentes disciplinas -sociología, antropología, psicología e iconografía- para explicar los fenómenos educativos y para reconstruir las actividades humanas de forma viva y concreta. Incluso el punto de vista epistémico de Foucault me ha ayudado a penetrar en las entrañas de las cosas, a definir el orden impuesto por el lenguaje y a los cuerpos sometidos al poder. Los cambios realizados por los movimientos feministas, en la década de los años setenta y ochenta, también hicieron que pusiera en discusión, reconduciéndola a la atención de nuestro ámbito, la tradicional dicotomía entre vida pública y privada. Así que utilicé el concepto de lo cotidiano como filtro de las transformaciones generales y como observatorio privilegiado de las actividades femeninas que han desarrollado la cultura educativa.

Por ejemplo, los cuidados maternos, que contribuyeron a la exploración del sentimiento medieval de la infancia, representan un elemento fundamental -aún no totalmente reconocido- de la evolución cultural. Así como la invención del amor cortés se atribuye a las capacidades empáticas de las damas representativas de las cortes francesas, que en el siglo XII-XIII fueron capaces de indicar un nuevo código ético. Fueron ellas a tomar en serio la importancia de la relación entre hombres y mujeres, inspirándolo con la idea de la reciprocidad visual: directamente a los ojos.

Tú, que eres una fina y excepcional estudiosa de la cultura educativa medieval, ¿por qué elegiste esta época?

Por muchas razones, que se resumen principalmente en dos. En primer lugar, porque considero que la tradición medieval es un recurso útil para el trabajo histórico sobre el género. El estudio de este período me empujó, por ejemplo, a investigar sobre el sentido de cambio expresado por los proyectos innovadores de Christine de Pizan (en el siglo xiv) en el ámbito femenino. Además, me permitió individuar las reglas del comportamiento visual que forjaron las relaciones interpersonales, en concreto las afectivas, entre adultos/niños y entre hombres/ mujeres. La observación de estos fenómenos asociados con la interpretación de los documentos iconográficos reforzó el estudio de aquellos aspectos -los modelos emotivos, las experiencias sensoriales y gestuales- considerados insignificantes y periféricos por los estudiosos de la historia intelectual.

¿Entonces el Niño medieval y La aventura de la mirada se sintonizan en esta longitud de onda?

De hecho, estos dos libros, publicados respectivamente en 1990 y 1995 , reflejan la elección de sustraerse de cuestiones cristalizadas en una historia de la educación 


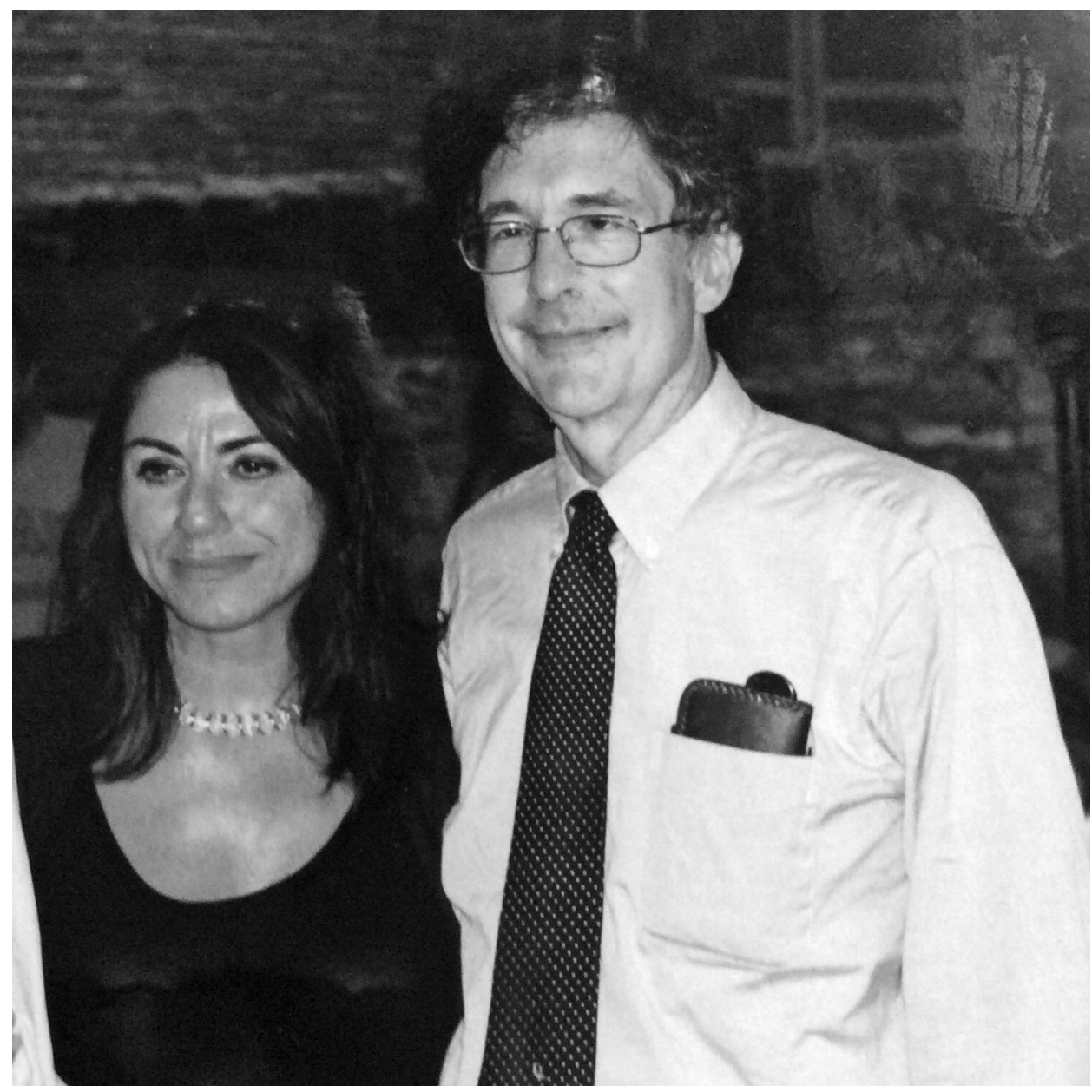

La profesora Giallongo con el profesor Howard Gardner con motivo de la concesión de la laurea honoris causa en la Universidad de Urbino (2003).

predominantemente masculina que ha hegemonizado, al menos en Italia, la atención -de forma, se podría decir, autorreferencial-sobre los únicos sujetos considerados portadores de un pasado digno de ser contado.

A continuación, sin tener en cuenta los límites impuestos por una periodización comprimida, por una compleja concurrencia de causas, en el estudio institucional y en las teorías científicas de los siglos XIX y XX.

Por tanto, si bien es cierto que idealmente las mujeres y los niños deben ser salvados de los naufragios también es cierto que de todas formas dejaron que se ahogaran en los abismos del anonimato, en apariencia falto de historia. Por consiguiente, el estudio del niño medieval recuperó en las teorías médicas, en la literatura vernácula secular y en las testimonios artísticos la precoz intuición sobre el 
mundo de los niños que los hizo reconocer por primera vez como seres sensibles, con necesidades de cuidados, inocentes y amantes del juego.

Por ejemplo, en Giotto. En la Capilla de los Scrovegni en Padua podemos ver el fresco más famoso de comienzos del siglo xiv, La nascita di Gesù. Concentrándonos en dos personajes principales, el artista deja entrever de los brazos extendidos hacia el niño recién nacido, del rostro y en concreto de los ojos de María, que acaba de dar a luz, una mezcla de felicidad, ternura y aprensión. Su mirada está clavada en el niño, que, no pudiendo moverse, debido al vendaje, corresponde con la misma intensidad. Son el contacto y la reciprocidad de las miradas los que dan sentido al mudo coloquio entre madre e hijo. Esta escena, junto con otras, apoya la creencia de que para amar es necesario ver. Y las pinturas de este período reproducen por primera vez la intimidad de los espacios femeninos, privados y cotidianos, con la mutualidad de las miradas, con reciprocidad de contacto físico, valorizando la libertad confidencial de los ambientes domésticos.

Pero las obsesivas instrucciones visuales dadas por el segundo milenio a las mujeres revelan a la vez las modalidades de control de la educación patriarcal sobre las culpables hijas de Eva, obligadas a sintonizarse emotivamente en un paralizante estado de vergüenza.

$Y$ este interés científico tuyo por las emociones ¿cómo se traduce en el nivel de la enseñanza universitaria?

Bueno, yo creo que la sinergia entre los dos ámbitos funciona óptimamente. Porque intento entrelazar las experiencias y los estilos emotivos de los estudiantes y de las estudiantes con la historia. Todavía en la actualidad la mayor parte de los escritos, en concreto de las chicas, me confiesa que su incapacidad para hablar en público depende de una sensación de inseguridad que inevitablemente da lugar a la vergüenza. Por consiguiente, ser capaz de enmarcar este estado de ánimo en un contexto que permite individuar la génesis cultural de los modelos educativos tradicionales que lo fomentaron es un primer paso para entender también la utilidad de la historia en la vida personal. Por otra parte, las iniciativas exitosas de mis cursos de postgrado, dedicados a las habilidades emotivas, me animan a seguir por este camino.

Además, basándose en tu experiencia, ¿cómo cambió el papel disciplinar en el establishment universitario?

Hubo diferentes pasos. En los años 70, todavía prevalecía el modelo idealista de la historia de las ideas pedagógicas, en un contexto nacional, en el que la pedagogía, obligada a desempeñar el papel de ancilla philosophiae, buscaba su propia autonomía científica. Autonomía que, en un complejo juego de interacciones, hizo oscilar, en un equilibrio precario, la relación entre pedagogía e historia. 
Con el resultado, a nivel institucional, que en momentos de crecimiento cualitativo y cuantitativo de la historia educativa (por ejemplo, en la última década del siglo $\mathrm{xx}$ ), se oponen a los demás de signo contrario. En esta alternancia de frenos y muelles, para simplificar, se detectan dos tendencias, también, antagonistas.

Por un lado, una planificación efervescente, por el otro, una especie de agonía institucional. Basta pensar en la disminución significativa del número de horas en diversos programas de estudios especializados del sector. Y la afirmación de un único campo disciplinar que, a nivel de la competencia, amenaza en gran medida con penalizar al pequeño grupo de historiadores de la educación en comparación con el gran ejército, bien organizado, de los pedagogos. Entre estos últimos, son particularmente temibles aquellos que creen, en el nombre de victorias pedagógicas, para poder prescindir de la historia. Sin tener en cuenta además de los daños infligidos a las universidades por los francotiradores del sistema clientelar académico...

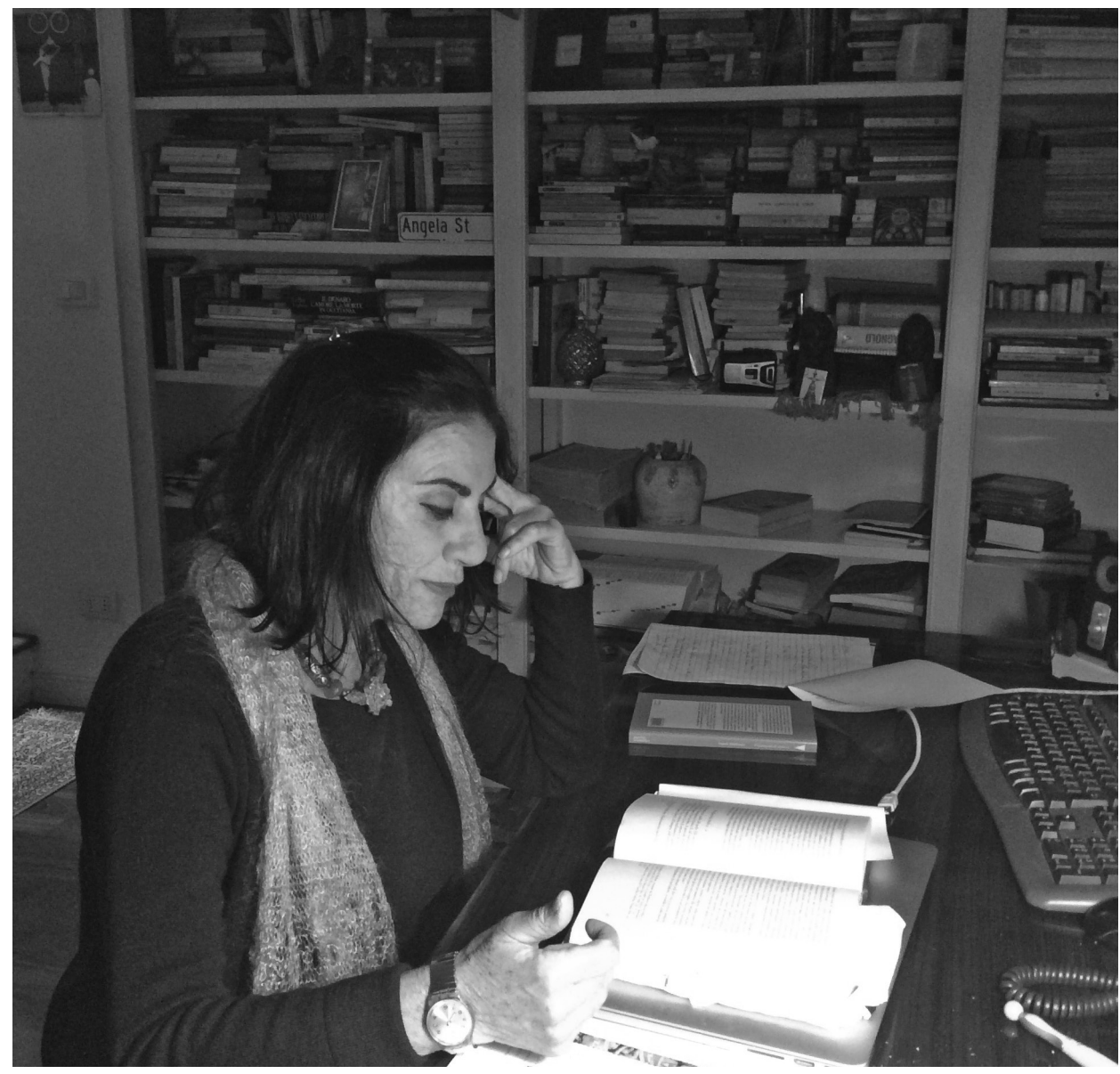

La profesora Giallongo trabajando en el estudio de su habitacion en Rimini. 


\section{LA PROFESORA ANGELA GIALLONGO Y EL FASCINANTE MUNDO DE LA IMAGINACIÓN 422 EN LA HISTORIA DE LA EDUCACIÓN ANTONELLA CAGNOLATI}

De becho, es una situación difícil. ¿Cómo se trabaja en este ambiente de "guerra»?

Esta circunstancia crítica, de alguna manera, estimula para permanecer en el frente de la efervescencia.

Si es la calidad de la investigación la que nos ayudó a encontrar el estímulo ¿tú en dónde encontraste la tuya en los últimos años?

Pues adentrándome en otros territorios, sin perder la oportunidad de aceptar el desafío cum laetitia.

Por ejemplo, las historias de la educación de género y de la infancia también se manifiestan en las diferentes culturas imaginativas que las caracterizaron en lugares y tiempos diferentes. La historia de la educación como disciplina académica tal vez todavía no considera el imaginario un tema prioritario, a pesar de que este haya sido de objeto de estudio y de investigaciones detalladas, muy importantes para nuestro sector, desde el siglo xx. Siguiendo este paradigma, pude entrever la génesis de esas costumbres mentales y actitudes sociales que, en gran medi$\mathrm{da}$, fortalecieron implícitamente no solo prejuicios y estereotipos, sino también experiencias emotivas negativas: la vergüenza, el miedo y el desprecio.

Las enseñanzas públicas, cultivadas por los griegos, a través de los mitos, tenían estos objetivos específicos. De hecho, la invención de la mujer serpiente había servido para perfeccionar la jerarquía entre los sexos como un principio básico de la civilización europea. A través de la desconcertante Gorgona, con su mirada mortal y su cabeza coronada por serpientes, se prepararon las bases para la difusión del simbolismo más importante en el campo de la desigualdad sexual. La herencia continúa todavía hoy. Su mito, después de todo, ha hecho y sigue siendo parte de las rutas didácticas de las escuelas italianas de todos los niveles.

Leí con placer e interés su último libro La mujer serpiente ${ }^{\mathrm{I}}$ (2013), entonces ¿cuál es la moraleja del mito de la Medusa?

Hacernos asistir, a través del análisis de los poderes formativos y deformativos de los mitos, al nacimiento de los miedos colectivos en relación con las mujeres y a las correspondientes representaciones visuales -ampliamente compartidasdel terror. Siguiendo este camino, me vi obligada a preguntarme sobre la gran influencia ejercida por los hostiles significados simbólicos atribuidos a la mirada femenina y a la serpiente, indudablemente relacionados en las diferentes culturas con la sangre menstrual.

La edición italiana se publicó en 2013 con el título La donna serpente: storie di un enigma dall'antichità al XXI secolo (Dedalo, Bari); fue traducido en español con el título La mujer serpiente. Historia de un enigma (Benilde, 20I5). Con este libro Giallongo ha conseguido el primer Premio del concurso nacional «Il Paese delle donne» (2013) y ha sido finalista del Premio Nacional de Divulgación Científica (2014). 
Los estudios sobre la Europa paleolítica y neolítica, sobre la protohistoria y sobre la civilización minoica, después de todo, nos invitan a revisar la comunicación simbólica, que heredamos del patriarcado, y a no respetar el estilo autoritario y jerárquico que lo justificó como único modelo social posible. La idea de que hayan existido sociedades denominadas «gilánicas»-basadas en el entendimiento, en el compañerismo, en la solidaridad y en la confianza recíproca entre los dos sexos- si bien para algunos no es emocionante, es, de todas formas, un antídoto para la visión que remontó el principio del proceso de civilización a la invención -considerada típicamente masculina- de la guerra y de la escritura. Y ¿qué es lo que leemos de esta civilización? Las historias y los símbolos que inspiraron, a partir del siglo viII a. C., la desmoralizadora idea de la mujer serpiente.

\section{¿Obtuviste resultados metodológicos?}

Creo que sí. La exploración de los usos simbólicos de la mirada y de la serpiente, y cómo se vincularon a la figura femenina, permite, por ejemplo, interpretar mejor las implicaciones de las actitudes sociales disciplinadas por las artes educativas: estas se pueden reconocer en concreto por el control obsesivo ejercido por la literatura patrística y medieval sobre el comportamiento visual de las mujeres.

Además, este tipo de estudio permite resistir a los pensamientos luctuosos del imaginario patriarcal, iluminar la negra noche de la alteridad, gracias al deseo de dar un sentido a la historia «de las cosas extrañas». Y así es por eso por lo que nos interrogamos sobre la mirada petrificante de la Medusa. 